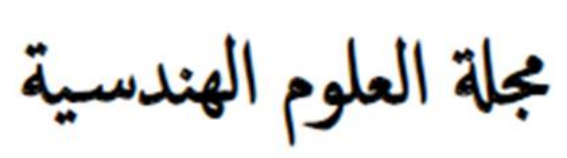

FES Journal of Engineering Sciences

\title{
Review of Punching Shear Strengthening Methods [Case Study: Application of Post Installed Shear Bolt Papers]
}

\author{
Ali Hussein Mohamed Ali ${ }^{1, *}$ and Aboalmaali Alamin Mohamed ${ }^{2,3}$ \\ 1 Civil Engineering Department, University of Bahri, Khartoum, Sudan \\ 2 Civil Engineering Department, University of Khartoum, Khartoum, Sudan \\ 3 Civil Engineering Department, Sudan University of Science and Technology, Sudan \\ * Corresponding author: Ali Hussein Mohamed Ali (e-mail: alibass288@hotmail.com).
}

Article history: Received 11 March 2020, Received in revised form 4 November 2020, Accepted 11 November 2020

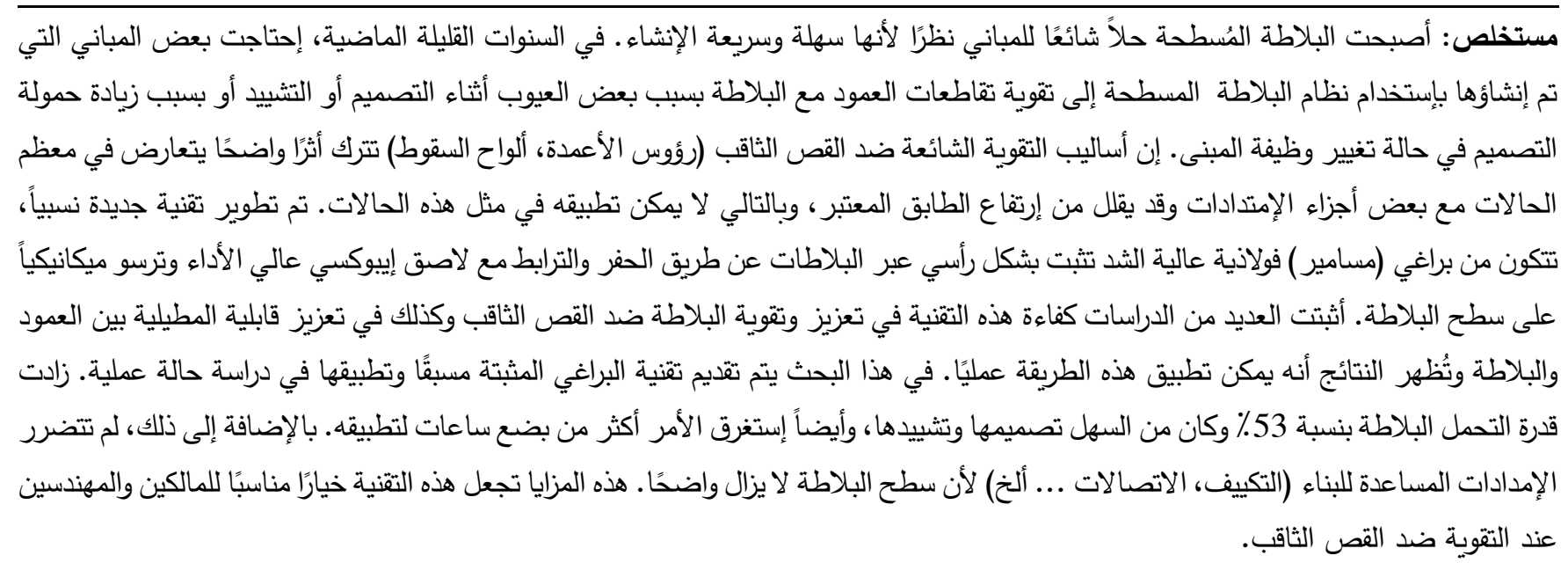

ABSTRACT Flats slabs became a common solution for buildings because they are easy and fast to build. In the last few years, some building that constructed using flat slab system required strengthening for column to slab junction due to either some imperfections during design, construction or due to increase of the design load in case of change of the building function. The common strengthen methods against punching shear (column heads, drop panels) leave an obvious trace which in most cases conflicts with some extensions parts and may reduce the height of the story considered, thus it can't be applied in such cases. A relatively new technique was studied, it consists of high tensile steel bolts installed vertically through the slabs by drilling and bonding with high-performance epoxy adhesive and mechanically anchored to the slab surface. Many studies validated the efficiency of the technique in strengthen against punching shear and also in enhancing the ductility of the slab-column connection and the results shows that the method can be applied in practice. In this paper, the post-installed bolts technique is presented and applied in a practical case study. The capacity of the slab enhanced by $53 \%$ and it was easy to design and construct. Also, it took not more than few hours for its application. In addition, the building extension utilities (Heating ventilation and air conditioning, communications...etc.) was not harmed because the slab surface remains clear. Those advantages make the technique a favorable option for owners and engineers when strengthening against punching shear.

Keywords: Ductility, Epoxy Adhesive, Post-Installed, Punching Shear, Shear Bolts, and Strengthening.

\section{INTRODUCTION}

Reinforced concrete slabs have many types that used in buildings construction, as shown in Fig. . The flat slab is the most popular among those types. It consists of flat plate rested directly on columns; it may conclude a drop panel or column capital. The flat slab system gained its popularity due to constructional benefits (reduction of building story heights, easy setting up of formwork, convenience for heating ventilation 
and air conditioning utilities layout and reinforcement simplification and thus low labor and material cost.), also its architectural benefits (higher architectural freedom in the distribution of internal partitions and furniture layout).

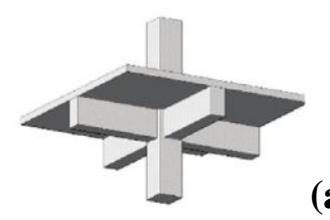

(a)
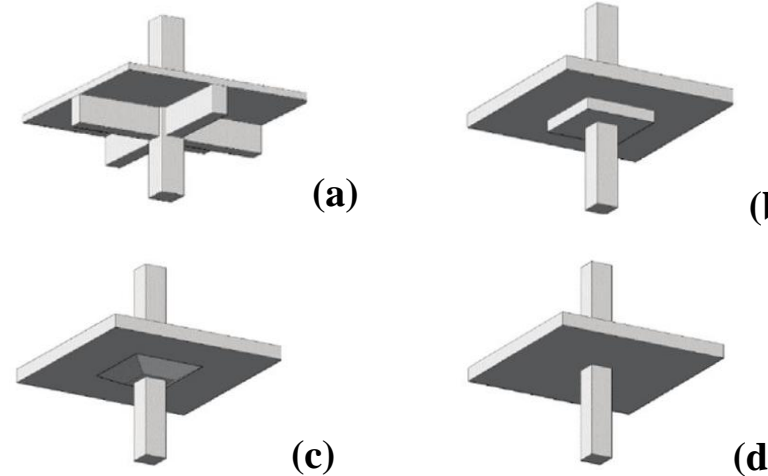

(b)

(d)

Fig. 1: a) Slab with beam, (b) Flat slab with drop panel, (c) Flat slab with column capita, (d) Flat plate.

Generally the design of the flat slab is governed by two limit states: the first is deflection (serviceability) which may lead to flexural ductile failure, and the second is bending and shear actions around the column area, that cause complex three-dimensional stress and strain states and result in principal tension stresses. These stresses are inclined with respect to the slab's plane which may cause non-ductile, sudden, and brittle punching shear failure which may lead to a progressive collapse, as shown in Fig. .

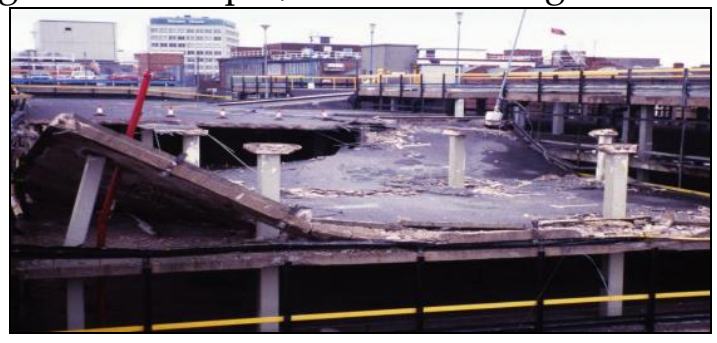

Fig. 2: Collapse of roof of car park due to punching shear.

In the last few years, some buildings which constructed using flat slab system required strengthening to increase the capacity of punching shear stresses. This may be due to uncertainties regarding structural safety (some imperfection during construction) or doubts about the stability (an increase of the design load in case of change of the building function). There are many methods used in retrofitting the lack of punching shear capacity of flat slabs.

This paper reviews common conventional and modern methods used for punching retrofitting.
Furthermore, focus on the development of the post-installed vertical shear bolts system and its application with a case study.

\section{LITERATURE REVIEW}

In practice, the well-known methods of strengthening slab-column connection involve adding a column head drop panel or combining them together, as illustrated in [Fig. (a) \& (b)]. The same concept of adding a column head is developed by replacing the concrete column capital with a stiffened plate connected with bolts (see Fig. (c)).
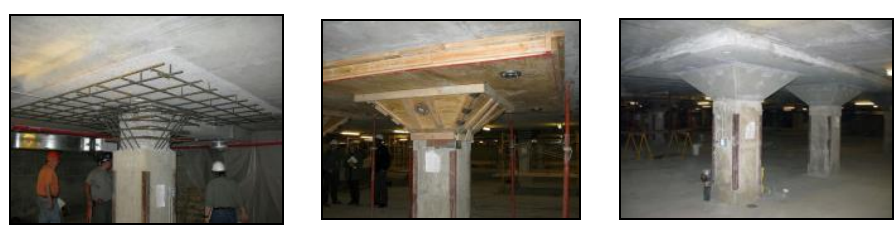

(a)

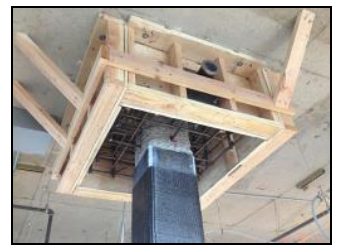

(b)

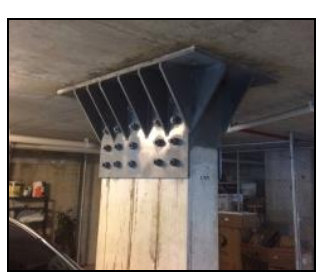

(c)
Fig. 3: Common strengthen methods used in practice.

A relatively new method that gained the interest of retrofitting engineers is the post installed vertical shear bolts. It consists of a penetrating shear bolt with a high strength tightened against the slab using a washer and a nut. A bonding material is used to ensure full grip to the drilled hole through the slab, as shown in Fig. 4.
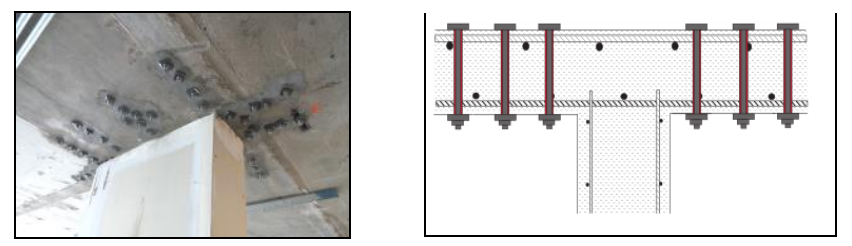

Fig. 4: Post installed vertical shear bolts system.

Adetifa \& Polak tested six slab specimens two with openings near the column, and three without openings the last one served as a reference to the test. All five specimens were reinforced with the proposed shear bolt system in which the bolt consists of a vertical headed rod with threads at 
the other end for anchored using a washer and nut, as shown in Fig. 5. The results showed a significant increase in the slabs ductility and strength [1]. It's noticed that the simplicity and efficacy of the system makes it a favorable retrofitting option.

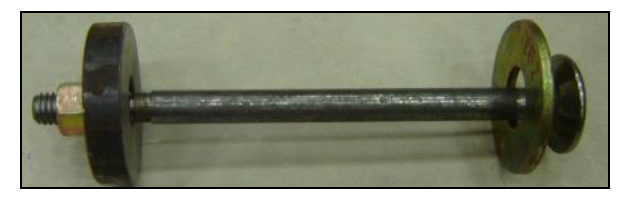

Fig. 5: Bolt components.

Hamed s. Askar investigated in the punching behavior of repaired with vertical studs (Fig. 6Error! Reference source not found.a) with different arrangements and to find the efficiency of the repairing technique. Eight specimens having same dimensions and flexural reinforcements and different concrete strength loaded until punching failure then the proposed system applied with different ratios of reinforcement to the damaged slabs and the tested again. From a comparison between observed punching load from the tested slabs with different design codes (ACI-318, CSA, NZS, and EC2) and the critical shear crack theory, it was found that the predicted punching capacity of the repaired slabs based on the CSCT and different codes is in close to the experimental values; but, the CSCT leads to less accord than design codes. Increasing the number of studs increases capacity for punching shear and also increases the slabs ductility [2].

Another study made by Hamed s. Askar to find out how far is the efficiency of post-installed prestressed bolts in enhancing the punching characteristics in retrofitted flat slabs damaged in punching shear. Four flat slab specimens with different thicknesses loaded until punching failure were retrofitted using post-installed steel bolts into two steps firstly the damaged concrete is cleaned and repaired, secondly number of calculated holes according to number of bolts were drilled and filled with adhesive epoxy to bond the bolts with the concrete and then a pre-stressing force applied to bolts and tightened to the slab surface using a plate, washer and a nut. The failure of the referenced slabs occurred with a distinguished sound which indicates to brittle failure. The technique increased cracking load. Also, the load at which the cracks occur increased almost the failure load of reference slabs and a greater punching load is noticed. The relation between the load and deflection of specimens showed that the deformation after repairing increased with the increase of the number of installed bolts. The experimental program result shows acceptable agreement with (ACI-318, CSA23.3-04) and reasonable agreement with (EC-2) which indicates that the ACI and CSA codes are more accurate in evaluating the punching load [3].

Improving punching shear capacity and ductility of slab-column structures at large lateral deformations is an important issue, especially in seismic zones. Wensheng $\mathrm{Bu}$ and $\mathrm{M}$. A. Polak constructed an experimental investigation on the behavior of retrofitted slab-column connections by vertical shear bolts under increasing regularly repeated lateral drift and constant gravity loading. Five slab specimens were retrofitted using shear bolts installed externally, as shown in Fig. 8 using the same bolts used by [1]. As a result, flexural failure occurred in retrofitted slabs and those without shear bolts failed by punching shear. This means that the shear bolts affect failure mode by changing it to ductile from brittle to failure. The connection capacity for lateral load increased after retrofitting. Also, he noticed that after a distance exceeding four times the slabs effective thickness the effect of bolts on the slab's behavior became little [4], [5].

Researchers used finite element modeling tools which facilitated testing and innovating efficient new retrofitting techniques. Also, reduce the time and cost of expensive laboratory testing, and gives more flexibility to simulate the loading and support conditions. Many types of research were carried out on strengthening for punching shear using FEMs. The basic concept of these studies is to create a finite element and validating it with 
previous experimental tests results after that a development process can be done by application of new configurations or materials on those validated models.

A comparative study by Khalil Belakhdar for evaluating shear bolts technique is made by creating a finite element model consisting of slab modeled as 8 node element with bolts and reinforcement bars modeled as on truss elements and a perfect bond between bolts and slab is assumed. The results obtained from the model came with an agreement with previous experimental results. The deflection of the slab is increased with the number added of bolts which is an indication that the slab behavior became more ductile accordingly the failure load increased [6].

As the efficacy of the system has become noticed by researchers, optimization of the system enticed Aikaterini Genikomsou and M. A. Polak. They examined retrofitted slabs by the system for the effect of amount and method of placement of shear bolts. Four models for interior column as shown in Error! Reference source not found.Fig. 9 (three with shear bolts) previously tested under static loading were analyzed. The amount of the bolts was increased by increasing the number of rows and also decreased by using less number of bolts in each row. For the placement method rectangular and radial arrangements are considered. It's noticed from the numerical results that the ACI 318-14 code is more conservative than EC2-2004 in predicting the failure load in comparison with the tested models. The radial arrangement (suggested by EC2-2004) increases the load capacity slightly more than the rectangular arrangement [7].

Some experimental studies were carried out to polish the system. One of those studies on that focused on the anchoring method. Three techniques were tested on slab specimens "large anchorage on the surface, a small anchorage on the surface and small embedded anchorage in addition to reference slab without shear bolts. No significant difference in the strength between the three anchoring methods [8]. As the small embedded anchorage plates is more viable and efficient from the aesthetics point of view (slab surface finishing) this makes it more preferable to the inhabitants of the strengthened building.

\section{CASE STUDY}

Public buildings (schools, Hospitals, General services...etc.) must be designed and constructed with much care for its importance and its occupancy. Also, those types of buildings must be checked and maintained annually. Any dereliction in any of those phases of the building life may lead to deterioration of its structural members.

\section{A. General description}

The case study is located in a public building constructed in the late 1990s. It consists of a basement and three floors. The plan area of the building can be described as large divided into several units. The main structural system consists of flat slabs with perimeter beams. The internal columns are square while outer columns are rectangular. In addition to one lift well surrounded by reinforced concrete walls.

The building served for a decade before it began to deteriorate. As a result, a full structural evaluation of the building is made which lead to various strengthening works, which can be summarized as follow:

i. Increase of raft foundation thickness.

ii. Enlargement of columns sections in some of the lower floors.

iii. Addition of columns capital heads for some columns in the upper floors.

The strengthening processes aimed to eliminate any deterioration and also to adapt the addition of two new floors this explains enlargement of columns (to increase its load carrying capacity). The spans between columns may be considered relatively long (up to $6.69 \mathrm{~m}$ in some locations) while the slab thickness was $200 \mathrm{~mm}$ and column dimensions were $(350 \times 350) \mathrm{mm}$ this obvious elements configuration leads to high concentration of stresses at column-slab junctions which may cause potential punching failure.

For the upper floors the columns capacity is 
sufficient to withstand its applied loading but in order to reduce stresses at column-slab junctions to prevent punching of the slab, columns are fitted with column capitals.

Another gained benefit of columns enlargement and addition of columns capitals is reducing the slab negative moments at columns.

From a structural design point of view and considering the applied loads on the building and the above configuration structural elements this may be considered as a design error.

\section{B. Structural evaluation}

The structural repairs and strengthening process took most of the time of the project rehabilitation and for the importance of the building, another structural evaluation based on the as-built drawings was initiated to assure the perfection of the strengthening works. These evaluations concluded that there is a potential punching shear problem in some locations at upper floors. As a remedial measure, a decision was made to strengthen those slabs to provide additional capacity against punching shear.

\section{Considered solutions}

The repair and/or strengthening method to be used in any particular situation depends on many technical and economical factors, and selection of the best method may be a complex task.

The first action that had been taken to strengthen those slabs came very late (after most of the finishing works were installed). At that time most of the HVAC systems, communications network, and false ceiling works were finished.

Two options were provided which were:

- Option (I): Fitting columns connection with columns capitals.

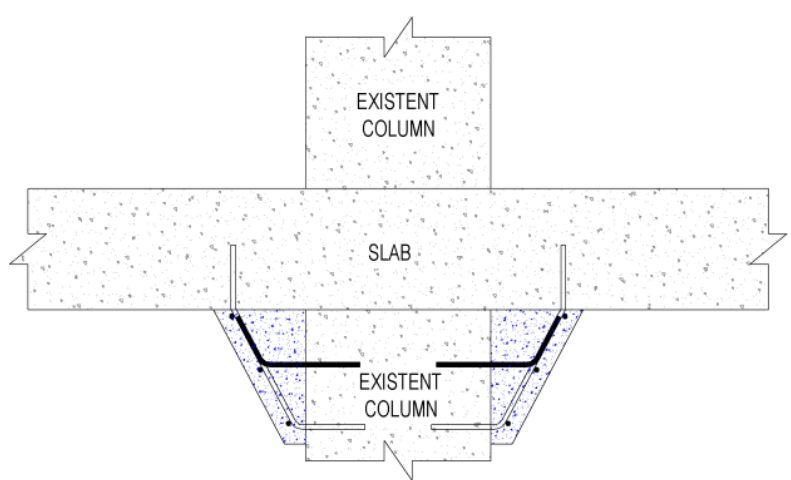

Fig. 6: Column head layout.

- Option (II): Using post Installed Shear Bolts
Technique.

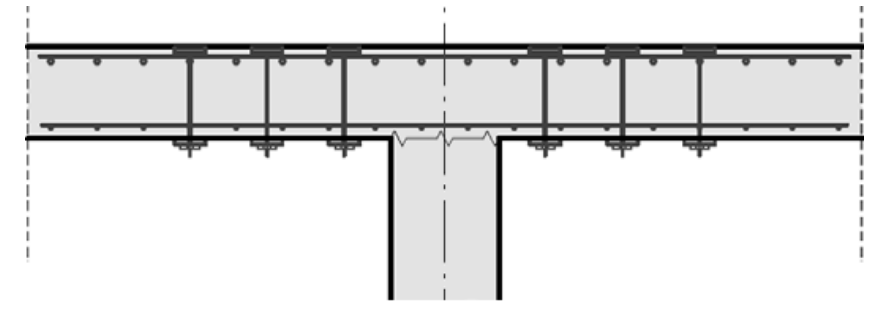

Fig. 7: Post installed shear bolts option.

In order to apply the option (I), special concrete mix, reinforcement fabrication and implementation to the slab and column is required. In addition, many utilities above and below the slab must be removed, demolished (partitions and tiles) or ruined (paintings) due to the concrete casting process. After that, more time will be consumed by relative concrete works (Formwork striking, concrete curing, etc.) and repairing or replacing what had been removed or ruined.

On the other hand, option (II) requires materials (shear bolts and epoxy adhesive) and the installation procedure of the bolts itself (drilling, fixing.etc.) that doesn't take more than few hours. When compared to option (I) less demolishing works (some partitions and tiles) is required and as there is no formwork to be struck and much less time required for the bonding material to gains its strength, the after retrofitting works can begin immediately after few hours because the slab capacity is immediately enhanced after installation procedure is done.

The project timeline was nearing its end and option (I) is time-consuming this made option (II) is more adequate. To determine the required amount of shear bolts the ACI code requirements for shear studs reinforcement [9] and (ACI 421.1R-08) [10] was followed.

\section{RESULTS AND DISCUSSION}

The main purpose of this paper is to present the design and construction of post-installed shear bolts technique. In order to design the required bolts for strengthening, the ACI-318 [9] and Joint ACI-ASCE Committee 421[10] gives recommendations for shear studs reinforcement. The design based on this code because it permits the use of mechanical anchoring of the bolts to the slab top and bottom surfaces (see Fig .8). Also, permits the orthogonal distribution of the 
punching shear reinforcement (see Fig. 9Error!

Reference source not found.).

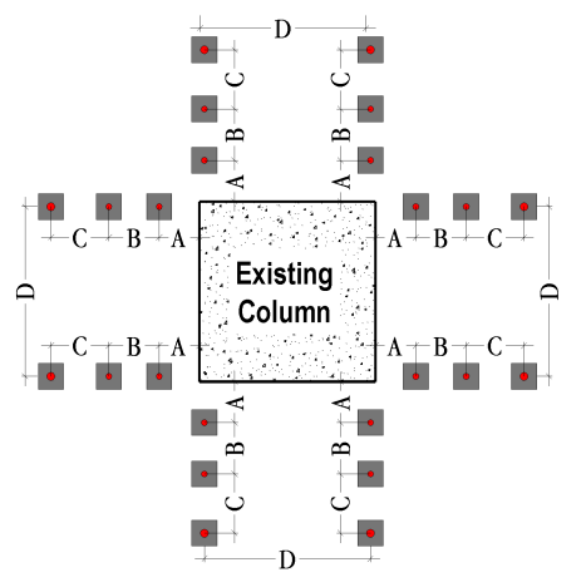
A: $\quad 80 \mathrm{~mm}$
B: $\quad 115 \mathrm{~mm}$
C: $\quad 115 \mathrm{~mm}$
D: $\quad 310 \mathrm{~mm}$

Fig. 8: Studs distribution.

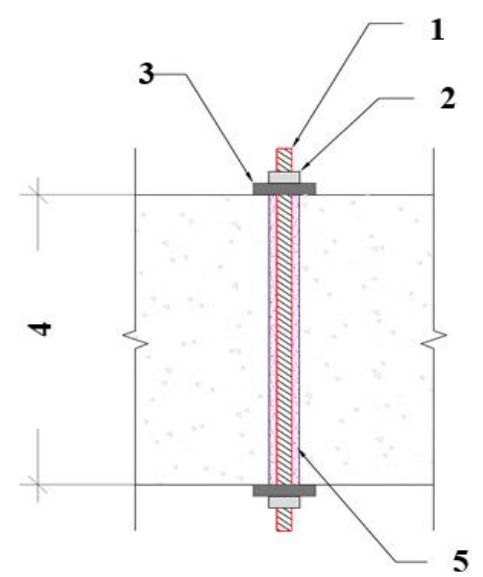

1: $12 \mathrm{~mm}$-Threaded bolt.

2: Nut.

3: $50 \times 50 \mathrm{~mm}$ Anchoring plate.

4: Slab depth.

5: High-performance epoxy adhesive.

Fig. 9: Stud Detail.

By strengthening using this technique the capacity of the slab enhanced by a significant amount. Inner and outer critical sections

Table I shows the capacity of the slab before and after retrofitting.

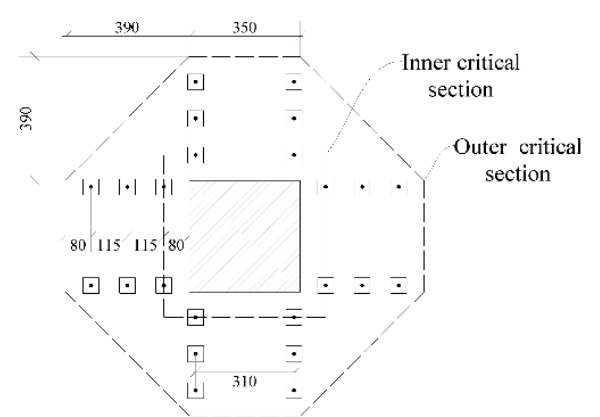

Fig. 10: Inner and outer critical sections

TABLE I: CAPACITY OF THE SLAB BEFORE AND AFTER STRENGTHENING AT INNER CRITICAL SECTION (D/2 FROM SUPPORT).

\begin{tabular}{c|c|c}
\hline \hline Variable & Before & After \\
\hline $\mathrm{Vu}(\mathrm{kN})$ & \multicolumn{2}{|c}{513.43} \\
\hline$\varnothing \mathrm{Vn}(\mathrm{kN})$ & 367.10 & 561.65 \\
\hline Capacity ratio $(\varnothing \mathrm{Vn} / \mathrm{Vu})$ & 0.72 & 1.09 \\
\hline Percentage of increase & \multicolumn{3}{|c}{$53 \%$} \\
\hline \hline
\end{tabular}

TABLE II: CAPACITY OF THE SLAB AFTER STRENGTHENING AT D/2 FROM
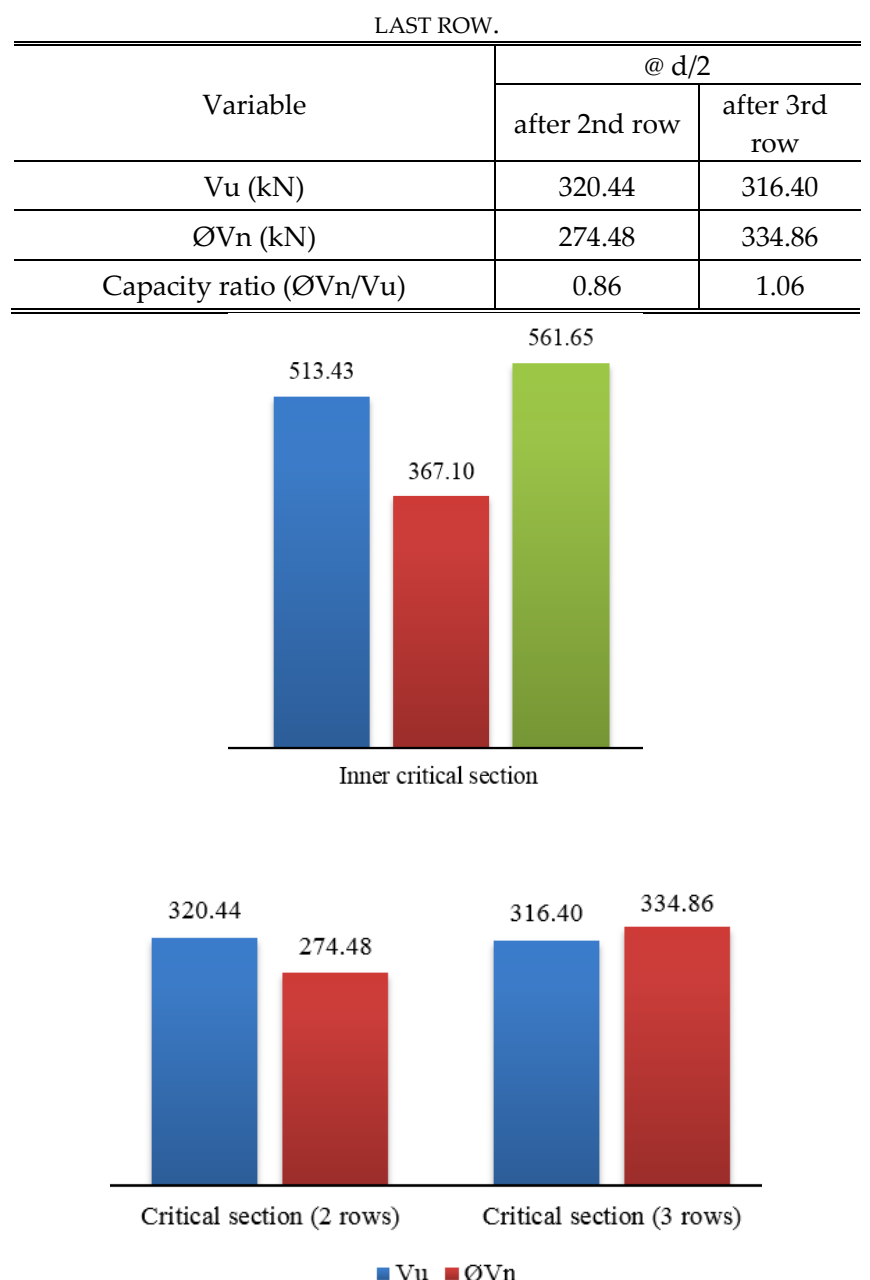

Fig. 11: Slab capacity after last bolts row.

\section{CONCLUSIONS AND RECOMMENDATIONS}

This paper has reviewed most of the common conventional and modern techniques to strengthen column-slab connections against punching shear and focused on the post-installed 
vertical shear bolts system by presenting its application in a practical case study. Following conclusions and recommendations can be drawn: It was concluded from the reviewed literature:

- The efficiency of the technique is ensured for internal column-slab connections with no openings and can be successfully used in practice.

- Application of system alters the column-slab connection to more ductile behavior; in this case, if the failure load is reached the slab will fail by flexure which is undoubtedly more preferable than the ordinary brittle punching shear failure.

- The system application range isn't limited to prevent the failure by punching shear only but also can be used to restore the capacity of failed slabs where the overall structural condition of the structure isn't damaged.

- If the bottom surface of the slabs has no false ceiling the bolts may be embedded and anchored below the surface and covered with high strength grout.

From the case study:

- The scheduled maintenance of structures can save it from deterioration and thus reduce the need for costly repair and rehabilitation works.

- The post-installed bolts technique was developed to have lesser construction time by using fast setting bonding materials and less retrofitting attendant works (shoring, curing ...etc.). This was a great benefit in the case study situation.

- Strengthening in the radial pattern can be difficult due to interference with flexural reinforcement which makes it difficult to apply without using reinforcement scanner. On the other hand, the orthogonal pattern is very easy to apply and has a lesser probability to interfere with flexural reinforcement.

- The method ensures that the concrete surface remains clear which guarantees that ceiling works and HVAC utilities remain at its position before and after retrofitting.

- From the economical point of view, option (I) has less cost than option (II). This may be referred to the required properties in the shear bolts (high tensile strength and threaded surface) which are imported from out of the county. But generally, the method is cost-effective relative to punching shear loads.

- It's recommended to use the system when the strength of the shear bolts and bonding materials are certified or tested.

\section{REFERENCES}

[1] B. Adetifa and M. A. Polak, "Retrofit Of Interior Slab Column Connections For Punching Using Shear Bolts," ACI Structural Journal, vol. 2, no. 102, pp. 268-274, 2005.

[2] H. S. Askar, "Repair Of R/C Flat Plates Failing In Punching By Vertical Studs," Alexandria Engineering Journal, vol. 54, no. 3, pp. 541-550, 2015.

[3] H. S. Askar, "Usage Of Prestressed Vertical Bolts For Retrofitting Flat Slabs Damaged Due To Punching Shear," Alexandria Engineering Journal, vol. 54, no. 3, pp. 509-518, 2015.

[4] W. S. Bu and M. Polak, "Seismic Retrofit of Reinforced Concrete Slab-Column Connections Using Shear Bolts," ACI Structural Journal, vol. 106, no. 4, pp. 514-522, 2009.

[5] W. Bu, "Punching Shear Retrofit Method Using Shear Bolts for Reinforced Concrete Slabs under Seismic Loading," p. 233, 2008.

[6] K. Belakhdar, "Nonlinear Finite Element Analysis of Reinforced Concrete Slab Strengthened with Shear Bolts," Jordan Journal of Civil Engineering, vol. 2, no. 1, pp. 32-44, 2008.

[7] A. Genikomsou and M. A. Polak, "Finite Element Simulation of Concrete Slabs with various Placement and Amount of Shear Bolts," Procedia Engineering, vol. 193, The Author(s), pp. 313-320, 2017.

[8] M. M. G. Inácio, A. Pinho Ramos, and D. M. V. Faria, "Strengthening Of Flat Slabs With Transverse Reinforcement By Introduction Of Steel Bolts Using Different Anchorage Approaches," Engineering Structures, vol. 44, pp. 63-77, 2012.

[9] ACI Committee 318, Building Code Requirements for Structural Concrete (ACI 318M-14). 2014.

[10] Joint ACI-ASCE Committee 421, "Guide to Shear Reinforcement for Slabs," 2008.

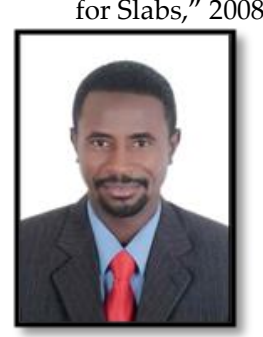

Ali Hussein Mohamed Ali

University of Bahri, College of Engineering \& Architecture.

Department of Civil Engineering.

Date of birth: 1971 - Elobeid (N. K. state)

Ph.D in Structural Engineering - Karary University [2011].

M.Sc in Structural Engineering - SUST [2001].

B.Sc in Structural Engineering - SUST [1996].

Major field of study: Civil Engineering [Structures]. 